\title{
TARGETING AND INSERTION OF THE CHOLESTEROL-BINDING TRANSLOCATOR PROTEIN INTO THE OUTER MITOCHONDRIAL MEMBRANE
}

\author{
Malena Rone ${ }^{1,2}$, Jun Liu ${ }^{1}$, Josip Blonder ${ }^{5}$, Xiaoying $\mathrm{Ye}^{5}$, Timothy D. Veenstra ${ }^{5}$, Jason C. \\ Young $^{3}$, and Vassilios Papadopoulos $1,2,3,4$ \\ ${ }^{1}$ Department of Biochemistry, Molecular and Cellular Biology, Georgetown University Medical \\ Center, Washington DC 20007, USA \\ ${ }^{2}$ The Research Institute of the McGill University Health Centre and the Department of Medicine, \\ McGill University, 1650 Cedar Avenue, Montreal, Quebec H3G 1A4, Canada \\ ${ }^{3}$ Department of Biochemistry, McGill University, 1650 Cedar Avenue, Montreal, Quebec H3G 1A4, \\ Canada \\ ${ }^{4}$ Department of Pharmacology and Therapeutics, McGill University, 1650 Cedar Avenue, Montreal, \\ Quebec H3G 1A4, Canada \\ ${ }^{5}$ Laboratory of Proteomics and Analytical Technologies, SAIC-Frederick Inc., National Cancer \\ Institute at Frederick, Frederick, Maryland 21702, USA
}

\section{Abstract}

Translocator protein (18-kDa, TSPO1), previously known as the peripheral-type benzodiazepine receptor, is an outer mitochondrial membrane (OMM) protein necessary for cholesterol import and steroid production. We reconstituted the mitochondrial targeting and insertion of TSPO into the OMM to analyze the signals and mechanisms required for this process. Initial studies indicated a formation of a mitochondrial 66-kDa complex through Blue Native-PAGE analysis. The formation of this complex was found to be dependent on the presence of ATP and the cytosolic chaperone Hsp90. Through mutational analysis we identified two areas necessary for TSPO targeting, import, and function: amino acids 103-108 (Schellman motif), which provide the necessary structural orientation for import, and the cholesterol-binding C-terminus required for insertion. Although the Translocase of the Outer Mitochondria Membrane (TOM) complex proteins Tom 22 and Tom 40 were present in the OMM, the TOM complex did not interact with TSPO. In search of proteins involved in TSPO import, complexes known to interact with TSPO were analyzed by mass spectrometry. The 66-kDa complex formation was found to be dependent on an identified protein, Metaxin 1, for formation and TSPO import. TSPO import into steroidogenic cell mitochondria was increased following treatment of the cells with cAMP. These findings suggest that the initial targeting of TSPO to mitochondria is dependent upon the presence of cytosolic chaperones interacting with the import receptor Tom70. The C-terminus plays an important role in targeting TSPO to mitochondria whereas its import into the OMM is dependent upon the presence of the Schellman motif. Final integration

\footnotetext{
${ }^{1}$ The abbreviations used are: ANT, anion nucleotide transporter; BN-PAGE, Blue-native polyacrylamide gel electrophoresis; FBS, fetal bovine serum; GD, geldanamycin; Hsp, heat shock protein; IMM, inner mitochondrial membrane; MPTP, mitochondria permeability transition pore; NB, Novobiocin; OMM, outer mitochondrial membrane; StAR, steroidogenesis acute regulatory protein; TOM, translocase of outer mitochondrial membrane; TSPO, translocator protein (18-kDa); VDAC, voltage-dependant anion channel

Address correspondence to: V. Papadopoulos, The Research Institute of the McGill University Health Center, 1650 Cedar Avenue, C10 -148, Montreal, Quebec H3G 1A4, Canada. Tel: 514-934-1934 ext. 44580; Fax: 514-934-8439; E-mail: vassilios.papadopoulos@mcgill.ca.
} 
of TSPO into the OMM occurs via its interaction with Metaxin 1. TSPO import into steroidogenic cell mitochondria is regulated by cAMP.

\section{Keywords}

Translocator protein; mitochondria; cholesterol transport; TOM complex; Hsp90 chaperone; cAMP

Translocator protein (18-kDa, TSPO), previously known as the peripheral-type benzodiazepine receptor, is an $18-\mathrm{kDa}$, high affinity, cholesterol- and drug-binding protein that is located in the outer mitochondria membrane (OMM). TSPO appears to contain five $\alpha$-helixes that span the OMM and assist with the transport of cholesterol from intracellular stores into the mitochondrial matrix, the rate-limiting step in steroid biosynthesis (1-3). TSPO has been shown to interact with the voltage-dependent anion channel (VDAC) and the adenine nucleotide translocase (ANT) comprising the mitochondria permeability transition pore (MPTP), which is located at the contact site between the inner and outer mitochondrial membrane (4-8). This mitochondrial localization at the contact site influences many of the biological functions in which TSPO participates, including cholesterol transport, protein import, cell proliferation, and apoptosis $(1 ; 2 ; 9-15)$. Due to its key role in these cellular functions, the targeting and insertion of TSPO into the OMM is thought to be tightly regulated.

Like the majority of mitochondrial proteins, TSPO is genetically encoded in the nucleus, translated in the cytosol, and then imported into mitochondria (16-18). Unlike many mitochondrial proteins of the matrix and inner mitochondria membrane, OMM proteins such as TSPO, do not have cleavable presequences for mitochondrial targeting. Instead, these proteins are targeted to the OMM through internal amino acid sequences (19). To date, OMM targeting signals have not been defined or predicted in multimembrane spanning proteins, and the signal or signals within TSPO are unknown.

The Translocase of the Outer Mitochondria Membrane (TOM) complex is a protein complex composed of receptors that recognize mitochondrial proteins for import and an aqueous pore for the translocation of proteins across the membrane (20). The TOM complex includes the key components Tom 22 and Tom40, the latter of which forms the translocation pore (21). Additional import complexes further direct the protein to its correct location in the OMM, inner mitochondrial membrane (IMM), intermembrane space, and mitochondrial matrix. The TOM receptor protein, Tom70, has been shown to loosely associate with the TOM complex and is important for the import of IMM metabolite carriers that have internal targeting sequences as well as larger hydrophobic proteins (22). Tom70 functions as a docking protein for both Hsc70 and Hsp90 through a central tetratriacopeptide repeat (TPR) domain (23), while its C-terminus is thought to bind mitochondrial proteins during import. Cytosolic chaperones, in particular Hsc70 and Hsp90, have been shown to assist with mammalian mitochondrial import, maintaining the newly made protein in a soluble, import-competent state (23-25). The chaperones that bind the mitochondrial protein dock onto Tom70; the mitochondrial protein is then transferred in an ATP-dependent manner to the core TOM complex for translocation (24).

The import of OMM proteins is an active area of investigation, as these proteins appear to use a diverse array of import mechanisms. C-terminal, tail-anchored OMM proteins, such as Bax and Bcl-xL, which span the OMM once by a transmembrane $\alpha$-helix, appear to require neither chaperones nor ATP for insertion (26). $\beta$-barrel OMM proteins, such as VDAC, require an additional OMM protein complex in addition to the TOM complex, the sorting and assembly machinery (SAM) complex, for correct insertion (27-29). The proposed mammalian SAM complex proteins include Sam50, the pore forming protein of the complex, Metaxin 1, which 
assists with protein integration into the OMM, and Metaxin 2, a cytosolic protein shown to bind to Metaxin 1 (30-32). The stoichiometry and stability of the SAM complex has not yet been firmly established. As TSPO appears to span the OMM via five $\alpha$-helixes; it is unknown whether TSPO is inserted directly into the OMM through the TOM complex or requires sorting through the SAM complex.

Previously, the results of Otera, et al. (33) have shown that TSPO does not use the traditional protein insertion pathway, but do not identify the pathway necessary for import. Our results presented herein further these studies by demonstrating that (i) during translocation to the OMM, TSPO interacts with cytosolic chaperones to facilitate an interaction with TOM70, (ii) there are specific amino acids necessary for the targeting of TSPO to the OMM, and (iii) once targeting is complete, TSPO insertion into the OMM is mediated through Metaxin 1, a member of the SAM complex. Interestingly, TSPO import into mitochondria was increased following treatment of hormone-responsive steroidogenic Leydig cells with cAMP, an event that parallels increased cholesterol transport and steroid formation by the cells (10). These findings support the existence of a novel three-step integration pathway for OMM proteins and suggest that protein import into steroid synthesizing mitochondria might be a cAMP- and thus hormoneregulated process.

\section{Material and Methods}

\section{Cell Culture}

HeLa cells (Lombardi Comprehensive Cancer Center Cell Culture Facility, Georgetown University), a well-established model used to study protein import into mitochondria, were maintained in DMEM supplemented with $10 \% \mathrm{FBS}$ at $37{ }^{\circ} \mathrm{C}$ and $6 \% \mathrm{CO}_{2}$. MA-10 mouse tumor Leydig cells, a well established model to study cholesterol transport into mitochondria and steroidogenesis, were a gift from Mario Ascoli (University of Iowa, Ames) and were maintained in DMEM/Ham's F12 (50:50) supplemented with 5\% fetal bovine serum (FBS) and $2.5 \%$ horse serum at $37{ }^{\circ} \mathrm{C}$ and $3.7 \% \mathrm{CO}_{2}$. In some experiments, confluent MA-10 cells were used to evaluate the effect of cAMP on mitochondria import. MA-10 cells were treated for two hours with 1mM 8-Bromo cAMP (Biomol, Farmingdale, NY) prior to mitochondrial isolation.

\section{Plasmid Construction}

The mouse TSPO cDNA coding sequence (5) was subcloned into pEGFP (CLONTECH Laboratories, Inc., Otsu, Shiga, Japan) at the Sac1 and BamHI sites (pEGFP-TSPO). For construction of TSPO with a truncated N-terminus, the QuickChange Site-Directed Mutagenesis Kit (Stratagene; La Jolla, CA) was used to generate a Sac1 mutation in the open reading frame of TSPO at the specified region. The vector was then digested with Sac1, gel purified, and ligated. TSPO with a C-terminal truncation was generated by creating a sequence verified stop codon mutation at amino acids 151 and 157 . For generating TSPO constructs carrying various deletions, the appropriate regions of TSPO were amplified by PCR, gel purified, ligated, and reinserted into the pEGFP vector. The fusion sites were verified by sequencing.

\section{Confocal Microscopy}

Confocal experiments were performed as stated previously (34) Briefly, MA-10 cells were grown on cover glass bottom dish, (Fluorodish, WPI; Sarasota, FL) until 70\% confluence. Plasmid constructs were transfected using Lipofectamine 2000 (Invitrogen; Carlsbad, CA). After 24 hours, cells were stained with 50nM Mitotracker CMX (Molecular Probes; Carlsbad, CA) for thirty minutes and viewed through an Olympus Fluoview FV1000 Laser Confocal Microscope. 


\section{Mitochondria Isolation}

Mitochondria were isolated by differential centrifugation as previously described (35). Briefly, HeLa cells or confluent MA-10 cells were washed twice with PBS, harvested in Buffer A (10mM Hepes-KOH, pH 7.5, .2 M Mannitol, .07 M Sucrose, 1mM EDTA , 1x Complete Protease Inhibitor Cocktail Tablet (Roche, Switzerland)) using a cell lifter, and centrifuged at $500 \times g$ for 10 minutes. The cell pellet was resuspended in 5 volumes of Buffer A, incubated at $4^{\circ} \mathrm{C}$ for 10 minutes and then centrifuged at $500 \times \mathrm{g}$ for 10 minutes. The cell pellet was resuspended in 5 volumes Buffer B (40 mM Hepes-KOH, pH 7.5, 500mM sucrose, $160 \mathrm{mM}$ Potassium Acetate and 10mM Magnesium Acetate, 1x Complete Protease Inhibitor Cocktail Tablets) and homogenized using an electric potter (glass-Teflon) for 10 passes. Once complete, cells were centrifuged at $500 \times g$ for $10 \mathrm{~min}$. The cell pellet was resuspended in 5 volumes Buffer B with a glass-glass homogenizer (20 passes) and centrifuged at $500 \times g$ for $10 \mathrm{~min}$. The supernatant was pooled and centrifuged at $10,000 \times g$ for 10 minutes at $4{ }^{\circ} \mathrm{C}$ to form a mitochondrial pellet. The mitochondrial pellet was resuspended in $1 \mathrm{~mL}$ Buffer B and centrifuged at $10,000 \times g$ for 10 minutes to enrich mitochondrial purity. Once complete, the mitochondria were resuspended in mitochondria import buffer (3\% BSA, $250 \mathrm{mM}$ sucrose, 5 $\mathrm{mM} \mathrm{MgCl} 2,80 \mathrm{mM} \mathrm{KCl}, 10 \mathrm{mM}$ MOPS-KOH, pH 7.2, $5 \mathrm{mM}$ ADP, and $10 \mathrm{mM}$ succinate (Sigma, St. Louis), 1x Complete Protease Inhibitor Cocktail Tablets) to give a final concentration of $1 \mathrm{mg} / \mathrm{mL}$ mitochondria for BN-Page import and $5 \mathrm{mg} / \mathrm{mL}$ mitochondria for sodium carbonate extraction. Mitochondria were kept on ice until use for no longer than 1 hour.

\section{Protein Import}

Radiolabeled TSPO was generated using the TNT® T7 Quick Coupled Transcription/ Translation System (Promega; Madison, WI) in the presence of $\left[{ }^{35} \mathrm{~S}\right]$-methionine (Amersham Biosciences; Piscataway, NJ) as performed previously (10) for one hour at $30^{\circ} \mathrm{C}$. Once complete, the reaction was terminated by the addition of one volume of $2 \times \mathrm{TT}$ buffer $(20 \mathrm{mM}$ Hepes- $\mathrm{KOH}$ pH7.5, 500mM sucrose, $80 \mathrm{mM}$ KOAc, $5 \mathrm{mM} \mathrm{MgOAc}_{2}$, $1 \mathrm{mM}$ Methionine). 5 $\mu \mathrm{l}$ of the TNT reaction was added to $50 \mu \mathrm{g}$ isolated mitochondria in import buffer for the stated times. Mitochondria were centrifuged at 10,000 $\times g$ for 10 minutes, solubilized with $1 \%$ digitonin buffer ( $20 \mathrm{mM}$ Tris-Cl, $0.1 \mathrm{mM} \mathrm{EDTA}, 50 \mathrm{mM} \mathrm{NaCl}, 10 \% \mathrm{w} / \mathrm{v}$ glycerol, $1 \%$ digitonin (Invitrogen) and $1 \mathrm{mM}$ PMSF) for 20 minutes on ice, and centrifuged at $10,000 \times g$ for 10 minutes. One-half of each sample was digested with $250 \mu \mathrm{g} / \mathrm{ml}$ proteinase K (Qiagen; Dusseldorf, Germany) at $4{ }^{\circ} \mathrm{C}$ for 10 minutes while the other half of the sample remained untreated.

\section{Blue Native (BN)-PAGE}

BN-PAGE was performed as described by Simpson (36). BN-PAGE loading dye (5\% w/v Coomassie Brilliant Blue G-250, $500 \mathrm{mM} \in$-amino- $n$-caproic acid, and $160 \mathrm{mM}$ BisTris, $\mathrm{pH}$ 7.0) was added to the sample supernatants, loaded onto a 4-16\% native gel (Invitrogen), and run at $130 \mathrm{~V}$. Once complete, the gel was transferred using a semi-dry transfer apparatus for one hour at $25 \mathrm{~V}$. The PVDF membrane was then fixed and dried. Then membrane was exposed to a multipurpose phosphor screen for 1-7 days and analyzed by phosphorimaging using the Cyclone Storage Phosphor System (Packard BioScience; Waltham, MA). Once complete, the membrane was then used for immunodetection. Image analysis was performed by Multi Gauge V3.0 from FujiFilm.

\section{Carbonate Extraction}

Mitochondrial protein import was analyzed as described by Fujiki et al. (37). After import, mitochondria were incubated at $0.5 \mathrm{mg} / \mathrm{ml}$ in $180 \mu \mathrm{l}$ of $0.1 \mathrm{M} \mathrm{Na}_{2} \mathrm{CO}_{3}(\mathrm{pH} 10.5)$ at $4{ }^{\circ} \mathrm{C}$ for 30 minutes. Forty $\mu \mathrm{l}$ of sucrose buffer (500 mM sucrose and $\left.0.1 \mathrm{M} \mathrm{Na}_{2} \mathrm{CO}_{3}, \mathrm{pH} 10.5\right)$ was added to the top of the sample and centrifuged at $180,000 \times \mathrm{g}$ for 30 minutes at $4{ }^{\circ} \mathrm{C}$ in a 
Beckman Coulter TLA-100 rotor. Trichloroacetic acid precipitation was performed on the supernatant, and both pellet and supernatant were analyzed by SDS-PAGE.

\section{Nickel-Sepharose Pull Down Assay}

The phosphate carrier $(\mathrm{PiC})$ was also generated from cell free transcription/translation reactions as stated previously (38). Radiolabeled TSPO and PiC were diluted 10-fold with reticulocyte lysate and incubated with either geldanamycin or novobiocin. Tom70-H3 was then added to the TNT reaction of either PiC or TSPO (23). After five minutes, apyrase was added to terminate the incubation reaction and $50 \mu \mathrm{l}$ of GTI buffer $(100 \mathrm{mM} \mathrm{KOAc}, 20 \mathrm{mM}$ Hepes- $\mathrm{KOH}$ pH7.5, 5mM MgOAc $2,20 \mathrm{mM}$ imidazole, $0.1 \%$ Triton X-100) was added. Nickel-Sepharose slurry was added to the mixture and incubated on an orbital shaker at $4{ }^{\circ} \mathrm{C}$ for 30 minutes. The resulting reactions contained $5 \%$ rectulate lysate reaction of TSPO or PiC containing the nickelSepharose slurry, the negative control reaction did not contain Tom70-H3, positive control, geldanamycin, and novobiocin treated samples contained $5 \mu \mathrm{M}$ Tom70-H3 and either $18 \mu \mathrm{M}$ geldanamycin or $1 \mathrm{mM}$ novobiocin. The beads were then washed twice with GTI buffer and once with GI buffer (lacking Triton X-100). The protein was eluted with 40 $\mu$ LLB with EDTA and separated by SDS-PAGE.

\section{Steroid Biosynthesis}

Steroid analysis was preformed as previously described (34). Briefly, MA-10 cells were plated in 24-well plates at a density of 50,000 cells/well. Cells were transfected after 24 hours with various GFP-TSPO constructs. Culture media were collected 24-48 hours post-transfection. In certain experiments, cells were washed with serum-free media and treated with $50 \mathrm{ng} / \mathrm{ml}$ hCG for two hours to determine the hormone-responsiveness of the cells. At the end of the incubation, media were collected. To determine maximal steroid production, the hydrosoluble substrate $22 R$-hydroxycholesterol $(10 \mu \mathrm{M})$ was added for two hours to the cells cultured in serum-free media. Progesterone production was measured by RIA in the media. Antiprogesterone antiserum was from MP-Biomedicals (Solon, $\mathrm{OH}$ ) and $\left[1,2,6,7-{ }^{3} \mathrm{H}(\mathrm{N})\right]-$ progesterone (specific activity: $17.5 \mathrm{Ci} / \mathrm{mmol}$ ) was from PerkinElmer Life Sciences.

\section{In-gel Digestion and MS Analysis}

Selected protein spots from HeLa extracts separated by BN-Page followed by 2D-SDS-PAGE were subjected to an in-gel digestion procedure as described elsewhere (39). Resulting in-gel digests were desalted using C18 Zip Tips (Millipore) before analysis by nano-flow reversedphase liquid chromatography (nanoRPLC) using an Agilent 1100 LC system (Agilent Technologies, Inc., Paolo Alto, CA) coupled online to a linear ion trap (LIT) mass spectrometer (LTQ, Thermo Scientific, San Jose, CA). Reversed-phase separations were performed using $75 \mu \mathrm{m}$ i.d. $\times 360 \mu \mathrm{m}$ o.d. $\times 10 \mathrm{~cm}$ long capillary columns (Polymicro Technologies Inc., Phoenix, AZ) that were slurry packed in-house with a 5- $\mu$ m, 300 A pore size Jupiter C-18 silica bonded stationary phase (Phenomenex Torrance, CA). After being injected with $5 \mu$ of sample, the column was washed for 20 minutes with $98 \%$ solvent A ( $0.1 \%$ formic acid in water, vol/ $\mathrm{vol})$ and peptides were eluted using a linear gradient of $2 \%$ solvent $\mathrm{B}(0.1 \%$ formic acid in $100 \%$ acetonitrile, vol/vol) to $85 \%$ solvent B for 110 minutes at a constant flow rate of $250 \mathrm{nl} /$ min. The LIT-MS was operated in a data-dependent mode in which each full MS scan was followed by seven MS/MS scans where the most abundant peptide molecular ions were dynamically selected for collision-induced dissociation (CID) using a normalized collision energy of $36 \%$. The temperature of the heated capillary and electrospray voltage (applied on column base) was $180^{\circ} \mathrm{C}$ and $1.7 \mathrm{kV}$, respectively. The CID spectra were searched against a non-redundant human protein database using SEQUEST (Thermo Scientific, San Jose, CA) and results were tabulated for each identified peptide/protein. 


\section{Transfection with siRNA}

Metaxin 1 siRNAs (5'-GCGCUGUCCUCAGAAUAAACCUGTT-3'; 5'CGUAAAGAGAAGUAUAAUGCCGACT-3';

5'GGAUAGACGCCAAGAACUAUGUGGA-3') were purchased from IDT (Coralville, IA) in a TriFecta kit. A hypoxanthine-guanine phosphoribosyltransferase (HPRT)-targeted positive control and a scrambled negative control were obtained from the same provider. MA-10 cells cultured in 100-mm dishes were transfected with $30 \mu$ Lipofectamine RNAiMAX (Invitrogen) and $20 \mathrm{nM}$ total of either the control siRNA duplex or protein-targeted duplexes for 48 hours. At the end of the treatment, media was changed and 3 days later cells were harvested and mitochondria were isolated for import studies.

\section{Real-Time qPCR}

$1 \times 10^{5}$ cells were harvested from the control and 8-Bromo cAMP treated MA-10 cells and used for RNA isolation to measure stated mRNA levels. RNA was isolated with an RNeasy Mini Kit (Qiagen) with optional DNase Digestion. The cDNA was then generated from Advantage RT-for-PCR kit (Clontech), using100ng RNA incubated with oligo(dT) primer. Analysis was performed with 7900HT Sequence Detection Agents (Applied Biosystems), primers used are stated in Table 1, TaqMan ${ }^{\mathrm{TM}}$ was from Applied Biosystems (Foster City, CA). All sequences were normalized to HPRT.

\section{Statistics}

Statistical analysis was performed using Prism version 4.0 (GraphPad Software, San Diego, CA). Group means were compared using student's t test or two-way ANOVA test followed by a Bonferroni column test. Data are presented as mean \pm sem, $p<0.05$ was considered significant.

\section{Materials}

Antibodies specific for TOM22 (Sigma), VDAC, Cox IV, Tom40 (Abcam; Cambridge, MA), Metaxin 1 (BD Bioscience; San Jose, CA) GapDH (Trevigen, Gaithersburg, MD) were purchased from the various vendors. StAR antibody was a generous gift from Dr. DB Hales (40). A specific rabbit polyclonal antibody was raised against the purified cytosolic fragment of human Tom70 (amino acids 111-608; manuscript in preparation). The TSPO polyclonal antibody was developed as previously described (41).

\section{Results \\ Import of TSPO}

To identify the import pathway of TSPO, we incubated cell-free, radiolabeled, in vitro translated TSPO with isolated HeLa cell mitochondria and monitored the formation of radiolabeled protein complexes through BN-PAGE by phosphoimaging. We have previously shown that the incubation of TSPO with isolated mitochondria results in import of a fully functional protein, capable of binding and transporting cholesterol in isolated steroidogenic mitochondria from MA-10 cells with consequent generation of steroids (10). As the TSPO import reaction with isolated mitochondria proceeded, we observed the presence of a radioactive band migrating at approximately $66-\mathrm{kDa}$ that increased in intensity with incubation time (Fig. 1A). A denaturing 2D SDS-PAGE of the BN-PAGE import reactions produced an 18 -kDa radioactive band, further confirming TSPO import into the mitochondria (data not shown). The presence of the TOM complex in the mitochondria was assessed by immunoblot analysis of proteins separated on BN-PAGE gels, electrotransferred on membranes, and blotted using antibodies against Tom 22 and Tom 40 . Both of these antibodies recognized immunoreactive proteins that migrated at $440-\mathrm{kDa}$, thus indicating the presence of the core 
TOM complex at the appropriate size though TSPO was not present in the complex. These data were confirmed in experiments in which the major import receptor Tom 20 was knocked down; its absence failed to affect TSPO import into mitochondria (data not shown). We further probed native membranes with an affinity-purified, anti-TSPO peptide-specific polyclonal antibody. Immunoreactive proteins were identified to migrate at $300-\mathrm{kDa}$ and $600-\mathrm{kDa}$. It should be noted that HeLa cells are known to have low levels of endogenous TSPO. In parallel studies using the rich-in-TSPO MA-10 cell mitochondria we identified immunoreactive TSPO at 66$\mathrm{kDa}, 300-\mathrm{kDa}$ and $600-\mathrm{kDa}$ (data not shown). As mature TSPO is known to form polymers (42) and also associate with various other IMM and OMM proteins (4;5), these large complexes likely contain both homo- and/or hetero-polymers of TSPO. The 66-kDa protein complex formed by newly imported TSPO was not detected in HeLa cells by immunoblot analysis as seen of steady-state endogenous TSPO. This may be due to the low levels of TSPO generated by the TNT radiolabeling kit, it must be remembered that TSPO antibodies directed towards the mature peptide are unlikely to recognize protein morphology altered during mitochondrial import.

To confirm TSPO import into isolated mitochondria, we performed a proteinase $\mathrm{K}$ digestion to degrade non-imported proteins. Protein import was performed at $4^{\circ} \mathrm{C}$ and $33^{\circ} \mathrm{C}$ and import reactions were terminated at 0 and 30 minutes. Samples were then divided into two sets, with and without proteinase $\mathrm{K}$ treatment. With the $4^{\circ} \mathrm{C}$ import reactions, the amount of $66-\mathrm{kDa}$ complex was greatly reduced relative to reactions at $33^{\circ} \mathrm{C}$. Proteinase $\mathrm{K}$ digestion of the $4^{\circ} \mathrm{C}$ reactions removed the 66-kDa protein complexes that were observable in untreated samples (Fig. 1B). In contrast, with the permissive $33^{\circ} \mathrm{C}$-import reaction, the $66-\mathrm{kDa}$ complex was resistant to proteinase treatment (Fig. 1B). These data suggest that the 66-kDa complex, under permissive conditions, is fully incorporated into mitochondrial membranes.

Further confirmation of TSPO membrane integration was obtained by carbonate extraction. Here TSPO was imported under permissive conditions and mitochondria were purified. These re-isolated mitochondria were treated with sodium carbonate to remove proteins that were associated with, but not integrated into, the OMM. Upon carbonate treatment and centrifugation, the majority of TSPO was found in the pellet with the mitochondrial membrane fraction, implying full incorporation of the protein into the OMM (Fig. 1C). As a positive control, the carbonate extraction experiment was performed with radiolabeled Tom70, an integral OMM protein, which displayed the same association profile as TSPO (Fig. 1C). In contrast, the soluble matrix protein Hsp60 was mostly found in the extracted supernatant fraction. Thus, the HeLa mitochondria have the necessary machinery to drive authentic TSPO import.

\section{TSPO associates with HSP90 and Tom70}

Heat shock proteins (HSPs), including Hsp90, are known to play an important role in delivering proteins to the OMM for import, interacting with Tom70 and assisting translocation in an ATP dependent manner (24). Therefore, to determine if TSPO interacts with Hsp90 for import into the OMM we incubated the purified C-terminal fragment of Hsp90 (C90) with TSPO import reactions into isolated mitochondria. $\mathrm{C} 90$ has previously been shown not to interact with mitochondrial proteins before import but does bind stably to Tom70, which outcompetes the HSP90 interaction and inhibits Tom70-dependent import (23). The addition of C90, resulted in a large reduction in TSPO import compared to control (Fig 2A, C), suggesting that import is dependent upon Hsp90 interaction.

To further test this hypothesis, we performed a series of BN-PAGE experiments. Considering that the chaperone-Tom70 pathway requires ATP for the function of $\mathrm{Hsp} 90$ or Hsc70, we depleted ATP from import reactions using apyrase. BN-PAGE analysis of the samples indicated that the membrane-integrated 66-kDa complex was reduced dramatically in the early 
stages of import (Fig. 2B). As Hsp90 seemed to function in TSPO targeting to Tom70, we next used the specific Hsp90 inhibitors geldanamycin (GD) and novobiocin (NB) to directly confirm the role of Hsp90 in TSPO import. GD obstructs the N-terminal ATP-binding domain of Hsp90 and inhibits the ATPase activity of the protein, resulting in a stalled complex and decreased translocation across the OMM $(24 ; 43)$. NB interferes with the targeting of proteins to the mitochondria by binding near the C-terminus of Hsp90, inhibiting substrate binding(44). NB also interferes with the docking of Hsp90 to Tom70. As shown in Figures 2B \& C, NB and GD significantly reduced import of TSPO compared to control ( $p<0.01$ by ANOVA). NB shows the greatest decrease in import; this is expected as NB would prevent TSPO from binding to Tom70 and associating with the mitochondria. GD is decreased, though not to the same extent as NB, caused by the prevention of cleavage of ATP, thus stalling TSPO on the mitochondrial membrane.

To further confirm that TSPO interacts with Tom70 for import, radiolabeled TSPO was incubated with the His-tagged Tom70 cytosolic fragment and then co-precipitated with nickelsepharose, reconstituting the targeting step as previously published. TSPO was recovered from the nickel-sepharose only when His-tagged Tom70 was present, indicating that TSPO interacts with Tom70 for import (Fig. 2D). GD and NB were incubated separately with the His-tagged Tom70 fragment and radiolabeled TSPO, and Tom70-associated material analyzed. GD did not inhibit the binding of TSPO to Tom70 as the recovery levels were similar to the control (Fig. 2D). This finding was similar to that observed with Hsp90-dependent precursor proteins, as GD only inhibits the ATP-dependant release of TSPO from the bound chaperone-Tom70 complex. In contrast, NB did prevent TSPO from associating with Tom70. Again, this finding matched the behavior of Hsp90-dependent precursors. Our results suggest that Hsp90 functions to target TSPO to the Tom70 import receptor by a mechanism typical of the chaperone-Tom70 pathway.

\section{$\mathrm{N}$-terminus is necessary but not sufficient to target TSPO to the mitochondria}

To identify the OMM-targeting sequence(s) of TSPO, we tested the localization of GFP-fused TSPO in MA-10 mouse Leydig cells. TSPO was tagged on either the N- or C-terminus to confirm that the presence of GFP did not interfere with the localization of the protein to mitochondria (data not shown). We then chose a construct in which GFP was linked at the Nterminus of TSPO to ensure that the cholesterol-binding domain on the C-terminus of the protein $(41 ; 45)$ would not be directly affected by the presence of the GFP moiety. A series of deletion constructs were generated to determine whether the $\mathrm{N}$-terminus is important for mitochondrial targeting (Fig. 3). Constructs in which the first 7, 28, 48, 68, and 85 amino acids were removed showed only a slight decrease in TSPO co-localization with the mitochondria, labeled with the Mitotracker CMX dye (Fig. 3A-F). Removal of amino acids 1-110 resulted in a loss of co-localization of TSPO with mitochondria and appearance of a diffuse pattern, consistent with an import defect (Fig. 3G).

As this region appeared necessary for TSPO import, we next examined the importance of amino acids found between residues $88-110$. A Schellman motif was predicted between amino acids 103-108. This motif, often found terminating $\alpha$-helical secondary structures, is stabilized through hydrophobic interactions between amino acids around a signature glycine residue (46). In TSPO, the Schellman motif is predicted to reside in the second intermembrane space loop, bridging the third \& fourth predicted transmembrane helices (Fig4a). Removal of these amino acids $(\Delta 103-108)$ resulted in focal aggregates of GFP-TSPO in areas adjacent to the mitochondria, as seen through a decrease in co-localization with Mitotracker (Fig. 3H). The point mutation of glycine 106 to alanine (G106A), that disrupts the Schellman motif by reducing flexibility, resulted in a similar profile as seen with TSPO $\Delta 103-108$ (Fig. 3I). The Schellman motif between amino acids 103-108 of TSPO thus appears to be critical for proper 
folding and/or membrane insertion. Though its role in localization and import remain open to investigation, the juxtamitochonrial location of aggregates suggests that the proteins are targeted, but not capable of import.

\section{C-terminus is necessary for targeting to the OMM}

As roughly two-thirds of the TSPO protein from the N-terminus can be removed without affecting the localization of the remaining protein to mitochondria, we then questioned whether the removal of the C-terminus affects TSPO localization. Generation of $\Delta 151-169$ and $\Delta 157$ -169 amino acid-deletion constructs caused a decrease in the localization of the protein to mitochondria with an increase in aggregation of GFP-TSPO (Fig. 3J, K). Considering that the cholesterol-binding domain of TSPO is present within the deleted region in TSPO $\Delta 151-169$, it was possible that this domain could play a role in the targeting of TSPO to the OMM. However, removal of region 148-157, which contains the cholesterol-binding domain, did not alter the TSPO/mitochondria co-localization pattern (Fig. 3L), suggesting that the domain does not play a role in TSPO import. Because the degree of TSPO/mitochondria co-localization decreases with the removal of the $\mathrm{C}$-terminus and although the cholesterol binding domain plays no role, it could be that some other feature of the C-terminus, such as the overall secondary structure, could play a role in TSPO localization with the OMM. A comparison of the Schellman motif and C-terminal sequences was made, revealing two conserved areas of high leucine content, amino acids 112-114 and 136, 137, and 141 (Fig. 4A). Point mutations of both sets of leucines (Leucine ${ }^{12-114}$ and Leucine ${ }^{136,137,141}$ ) into alanines did not alter TSPO co-localization with mitochondria (Fig. 3M, N).

\section{Inhibition of import of TSPO mutants}

In the above-described GFP-TSPO/mitochondria co-localization experiments, several constructs displayed reduced degrees of co-localization. To confirm that reduced colocalization reflects reduced TSPO import into mitochondria, BN-PAGE of in vitro import reactions was performed using $\left[{ }^{35} \mathrm{~S}\right]-\mathrm{TSPO}$ mutant constructs. Notably, the Schellman motif mutant $\Delta 103-108$ could not be imported to the 66-kDa complex (Fig. 4B). The import of TSPO carrying the G106A point mutation also resulted in the greatly decreased import of the 66-kDa protein complex, although not to the extent seen with the $\Delta 103-108$ TSPO construct (Fig. 4B). The ability to import was then tested for the TSPO constructs in which the C-terminal domains, 151-169 and 157-169, were removed. Both deletions clearly abolished the import of the 66$\mathrm{kDa}$ complex in isolated mitochondrial (Fig. 4C). To determine whether the alteration of the structure of the C-terminus results in the inhibition of TSPO import, the Leucine ${ }^{112-114}$ and Leucine $^{136,137,141}$ TSPO point mutants were analyzed by BN-PAGE. Leucine ${ }^{112-114}$ did not show an effect on TSPO import (Fig. 4D). However, the Leucine ${ }^{136,137,141}$ TSPO mutant showed a significant decrease in the import of the 66-kDa complex (Fig. 4D), although its level of synthesis in vitro was similar to the Leucine ${ }^{112-114}$ mutant (Fig. 4E). This result differs from the results of confocal microscopy in which the Leucine ${ }^{112-114}$ TSPO mutant was found to colocalize with mitochondria. This apparent discrepancy could be due to differences between the in situ and in vitro situations, including the highly concentrated intracellular environment, which favor TSPO import and alleviate partial import defects. Overall, the in vitro and live cell results support an important role of the Schellman motif and sequences within the Cterminus of TSPO for import.

\section{Functional evaluation of TSPO import in steroid biosynthesis}

As TSPO controls the rate-limiting step in the production of steroids, cholesterol tranport into mitochondria, increasing the TSPO protein concentration in the OMM by transient transfection with a TSPO construct was shown to increase progesterone production by MA-10 mouse Leydig cells in culture (34). To investigate the functional role of altered import of TSPO 
mutants previously evaluated by confocal microscopy and BN-PAGE analyses, we measured progesterone production in MA-10 cells transfected with wild-type and mutated TSPO constructs (Fig. 4). As the constitutive expression of TSPO in MA-10 cells was not silenced, a basal level of progesterone production was observed. However, transfection of MA-10 cells with GFP-TSPO resulted in a marked 2.5-fold increase in progesterone production (Fig. 4F; $p<0.01$ by Student's t-test), consistent with previous findings (34). Transfection with TSPO in which the Schellman motif was mutated (G106A) did not affect basal progesterone formation but did not cause a similar increase seen by transfection with wild-type GFP-TSPO. The results obtained with the G106A TSPO mutant support the data obtained in situ by confocal microscopy and in vitro using BN-PAGE, indicating that such mutants are not imported and therefore not functional in cholesterol transport. The Leucine ${ }^{136,137,141}$ mutant showed progesterone levels near basal levels, suggesting that while this mutant may be imported into the OMM, it was not functional in the transport of cholesterol into the mitochondrial matrix. C-terminal mutants also failed to increase progesterone production, consistent with an import defect. The finding that removal of the cholesterol-binding domain in the TSPO $\Delta 151-169$ construct resulted in the reduction of basal progesterone production is in agreement with previous findings $(10 ; 45)$.

\section{Metaxin 1 is necessary for TSPO import}

Considering the data presented above that TSPO does not stably associate with the core TOM complex during import, we undertook a detailed analysis of the identification of proteins involved. Using a combination of BN-PAGE and 2D-SDS-PAGE followed by mass spectrometric analysis of proteins present in all spots separated from the $66-\mathrm{kDa}$ complex, as well as the stable $800-\mathrm{kDa}$ complex, we identified a number of proteins of interest (Table 2). Among the identified proteins present in the 66-kDa protein complex was Metaxin 1. Metaxin 1 was shown previously to be present in MA-10 cells and be induced by hormone-treatment in a manner parallel to steroid synthesis (47). Probing BN-PAGE immunoblots with an antiMetaxin 1 antibody showed that the protein identified migrated at a similar molecular size to $\left[{ }^{35} \mathrm{~S}\right]$-TSPO (Fig. 5A).

Metaxin 1 is the mammalian homolog of yeast Sam37 (also called Mas37/Tom37), a component of the SAM complex known to function in the stable integration of OMM $\beta$-barrel proteins $(29 ; 32)$. Metaxin 1's primary role in the OMM is to function as a receptor in the SAM complex (48) It was possible that Metaxin 1 could play a role in TSPO import and to address this, an siRNA duplex that targets Metaxin 1 was used to knock down its expression.

Mitochondria were isolated from MA-10 cells that had been treated for 5 days with $20 \mathrm{nM}$ of either a siRNA complex toward Metaxin 1 or a scrambled negative control. Figure 5C shows that the siRNA successfully reduced Metaxin 1 protein levels compared to the scrambled siRNA control. Moreover, the basal levels of the inner mitochondrial membrane protein COXIV were unaffected by Metaxin 1 silencing, though endogenous TSPO levels were slightly decreased. BN-PAGE of import into the mitochondria from Metaxin1 knockdown cells showed that the rate of TSPO import at the 66-kDa complex was diminished, compared to mitochondria from scrambled siRNA and untreated cells (Fig. 5B). This data, quantified in Figure 5D ( $p<0.05$ by ANOVA), suggests that Metaxin 1 is involved in TSPO import into the OMM.

\section{Cyclic-AMP stimulated mitochondria increases TSPO import}

Steroidogenesis is initiated upon the transfer of cholesterol from the OMM to the IMM where it interacts with CYP11A1 to be converted into pregnenolone. This transfer of cholesterol is activated via a cAMP-dependent pathway, resulting in an increase in protein synthesis, protein phosphorylation and lipid synthesis (49). To determine if activation of steroidogenesis would alter mitochondrial protein import, MA-10 cells were incubated with $1 \mathrm{mM}$ cAMP for two hours, the point in which maximal rates of steroid production are seen in vitro, and the 
mitochondria were isolated (50). Upon initiation of TSPO mitochondrial import, a 1.7-fold increase of $66-\mathrm{kDa}$ TSPO was observed in mitochondria isolated from cAMP-treated cells within the first 5 minutes followed by a 2.2- and 1.8-fold induction over basal at 15 and 30 min, respectively (Fig. 6A, B). The effect of cAMP was statistically significant $(p<0.05$ by ttest). To determine if gene and protein expression levels were altered both qPCR and western blot analysis were performed. qPCR results showed no increase upon cAMP treatment of the Tom 40 pore for OMM protein import and Tim 22 for IMM protein import. Metaxin 1 showed a slight but not significant increase upon cAMP stimulation (Fig. 6C). While the 2 hour cAMP treatment is too short for most transcriptionally-based changes in protein expression, translation- or degradation-based regulation can cause faster effects. However, upon immunoblot analysis there were no significant increases seen in any mitochondrial proteins including Metaxin1 (Fig. 6D). StAR protein expression, which is a cAMP-induced protein, was also measured to confirm the 8-bromo cAMP activity. StAR mRNA levels were increase by 10 -fold (data not shown) and there was also a pronounced induction of StAR protein levels (Fig. 6D). This suggests that while the mechanisms necessary for mitochondrial import are being up-regulated, the increase in TSPO import is not due to an increase in mitochondria import proteins. It is possible however that changes in the composition $\mathrm{f}$ protein complexes and protein-protein interactions needed for import could occur.

\section{Discussion}

In the above experiments, we determined the pathway for the targeting and insertion of the multi-membrane spanning protein, TSPO, into the OMM. A schematic representation of the steps of the process is shown in Figure 7. The initial targeting of TSPO to mitochondria has been shown to be dependent on the presence of the cytosolic chaperones Hsp90 and most likely Hsc70 as well as their interactions with Tom70 upon arrival at the OMM. As this first step shows, these early interactions of the cytosolic chaperones and Tom70 depend on the proper binding of TSPO to the chaperones. Targeting of chaperone-TSPO complexes to Tom70 is the second step. The Tom70 complex formed at this stage may be relatively unstable and although not detected in the BN-PAGE, it can be reconstituted with purified Tom70. The third step of TSPO import into the OMM is insertion into the membrane. This is a temperature and ATPdependent process involving the release of TSPO from the chaperones and Tom70. Metaxin1 functions at this step to boost the kinetics of insertion. After insertion, TSPO becomes resistant to proteinase $\mathrm{K}$. The third step requires formation of specific secondary structures including the Schellman motif, which probably aids integration of the third and fourth transmembrane domains of TSPO into the OMM. In steroidogenic and hormone-responsive MA-10 Leydig cells, the rate of import into the isolated mitochondria can be accelerated following treatment with cAMP (Fig. 7; yellow arrow). These conformational requirements suggest that the 66$\mathrm{kDa}$ complex contains TSPO in a native folded state. The native complex is most likely a homooligomer of TSPO as has previously been observed. The $66-\mathrm{kDa}$ complex then matures into the final complexes of up to $800-\mathrm{kDa}$ which are observed in steady-state mitochondria of endogenous TSPO. These complexes may include the known TSPO interacting proteins VDAC and ANT, further identified by mass spectrometry to be present in this complex, as well as other proteins. This process of TSPO import constitutes a novel pathway for protein import into the OMM.

As mentioned earlier, our results broadly support the conclusion of Otera et al. (33) that TSPO is inserted into mitochondria via a novel pathway. The authors identified a $66-\mathrm{kDa}$ TSPO complex by BN-PAGE upon import into HeLa mitochondria. They also demonstrated that Tom22, Tom20, Tom40, and Sam50 were not involved in TSPO import whereas Tom70 played a role in TSPO targeting to mitochondria, in agreement with our findings. They hypothesized the importance of other unidentified mitochondrial proteins for TSPO and other protein import. We now confirm these findings and extend them by providing evidence that Hsp90 and 
Metaxin1 also function in the targeting and insertion of TSPO into the OMM. Although the role of heat shock proteins in TSPO mitochondrial import was previously discussed, the interaction was described as ATP-independent, a conclusion that is not supported by our data. Our demonstration of ATP-dependent import is in fact consistent with established work on the Tom70 pathway and with current models of Hsp90 and Hsc70 activity.

We furthermore report that Metaxin1 and the C-terminus of TSPO are critical for TSPO insertion into the OMM. These findings might explain the mechanism of import of a number of proteins into the OMM. Sam 37 has been shown to play a role in the import of $\alpha$-helical, Cterminal-targeted TOM proteins, such as Tom 22 and small Tom proteins. This finding suggests that the interaction of TSPO via its C-terminus with Metaxin 1 is necessary for its complete import into the OMM. Slight alteration of the $\alpha$-helix of the C-terminus could interfere with this import, as seen with the inhibition of Leucine ${ }^{136,137,141}$ mutant import by BN-PAGE. Metaxin 2, a cytosolic protein shown to interact with Metaxin 1 at the OMM, could also play a role in import. Moreover, we identified the amino acids critical for insertion of the protein into the OMM and demonstrated the functional significance of TSPO insertion and import into mitochondria of steroidogenic cells in which TSPO, a cholesterol-binding protein, functions in cholesterol import, the rate-determining step in steroid biosynthesis.

The final step of TSPO import is the functional integration into the OMM. Antibody detection of TSPO on the BN gel membrane identified a major 800-kDa complex while not recognizing the protein migrating at $66-\mathrm{kDa}$ either due to limited amounts of the protein or accessibility of the antibody to the antigen. We propose that the $800-\mathrm{kDa}$ complex represents the biologically functional population of TSPO in the OMM. Mass spectrometric analysis of these complexes revealed that at the 66-kDa complex in HeLa cells, in addition to Metaxin 1, VDAC1 was identified. As metaxin 1 assists with $\beta$-barrel protein insertion into the OMM, it is possible the close association of TSPO with VDAC could form here, allowing a foundation for a larger protein complex to form. Mass spectrometric analysis of the 800-kDa complex identified the isoforms of VDAC and anion nucleotide transporter (ANT). As it is known that TSPO physically and functionally interacts with VDAC $(4 ; 5 ; 34)$ and ANT (5) and that they are part of the mitochondrial permeability transition pore (MPTP) (15), we propose that these complexes represent the contact sites between the OMM and the IMM, a place where TSPO is concentrated (7). As contact sites have been suggested to play a role in cholesterol transport, apoptosis, energy metabolism and protein transport; further understanding of the proteins involved in this area could lead to a deeper understanding of the function of contact sites (51-53). Interestingly, at the $800-\mathrm{kDa}$ protein complex, mass spectrometry identified other known mitochondrial proteins, that is, fatty synthase and apolipoprotein AI and AII, likely participating in cholesterol transport into mitochondria, needed for steroid formation in steroidogenic cells and membrane biogenesis in proliferating cells.

In conclusion, the findings reported herein using as a model TSPO support the existence of a novel three-step integration pathway for OMM proteins and suggest that such protein import might be a cAMP-regulated process.

\section{Acknowledgments}

*This work was supported by National Institutes of Health grant ES07747 and in part HD37031 (to V.P.). V.P. was also supported by a Canada Research Chair in Biochemical Pharmacology. J.C.Y. holds a Canada Research Chair in Molecular Chaperones. The Research Institute of MUHC was supported by a Center grant from Le Fonds de la recherche en santé du Québec. We thank Dr. M. Ascoli (University of Iowa, Iowa City) for the MA-10 Leydig cell line and the National Hormone and Pituitary Program (NIDDK, NIH) for the hCG 


\section{References}

1. Papadopoulos V, Baraldi M, Guilarte TR, Knudsen TB, Lacapere JJ, Lindemann P, Norenberg MD, Nutt D, Weizman A, Zhang MR, Gavish M. Translocator protein (18kDa): new nomenclature for the peripheral-type benzodiazepine receptor based on its structure and molecular function. Trends Pharmacol. Sci 2006;27:402-409. [PubMed: 16822554]

2. Lacapere JJ, Papadopoulos V. Peripheral-type benzodiazepine receptor: structure and function of a cholesterol-binding protein in steroid and bile acid biosynthesis. Steroids 2003;68:569-585. [PubMed: 12957662]

3. Murail S, Robert JC, Coic YM, Neumann JM, Ostuni MA, Yao ZX, Papadopoulos V, Jamin N, Lacapere JJ. Secondary and tertiary structures of the transmembrane domains of the translocator protein TSPO determined by NMR. Stabilization of the TSPO tertiary fold upon ligand binding. Biochim. Biophys. Acta 2008;1778:1375-1381. [PubMed: 18420025]

4. McEnery MW, Snowman AM, Trifiletti RR, Snyder SH. Isolation of the mitochondrial benzodiazepine receptor: association with the voltage-dependent anion channel and the adenine nucleotide carrier. Proc. Natl. Acad. Sci. U. S. A 1992;89:3170-3174. [PubMed: 1373486]

5. Garnier M, Dimchev AB, Boujrad N, Price JM, Musto NA, Papadopoulos V. In vitro reconstitution of a functional peripheral-type benzodiazepine receptor from mouse Leydig tumor cells. Mol. Pharmacol 1994;45:201-211. [PubMed: 8114671]

6. Veenman L, Shandalov Y, Gavish M. VDAC activation by the $18 \mathrm{kDa}$ translocator protein (TSPO), implications for apoptosis. J. Bioenerg. Biomembr 2008;40:199-205. [PubMed: 18670869]

7. Culty M, Li H, Boujrad N, Amri H, Vidic B, Bernassau JM, Reversat JL, Papadopoulos V. In vitro studies on the role of the peripheral-type benzodiazepine receptor in steroidogenesis. J. Steroid Biochem. Mol. Biol 1999;69:123-130. [PubMed: 10418986]

8. Galiegue S, Tinel N, Casellas P. The peripheral benzodiazepine receptor: a promising therapeutic drug target. Curr. Med. Chem 2003;10:1563-1572. [PubMed: 12871127]

9. Galiegue S, Casellas P, Kramar A, Tinel N, Simony-Lafontaine J. Immunohistochemical assessment of the peripheral benzodiazepine receptor in breast cancer and its relationship with survival. Clin. Cancer Res 2004;10:2058-2064. [PubMed: 15041726]

10. Hauet T, Yao ZX, Bose HS, Wall CT, Han Z, Li W, Hales DB, Miller WL, Culty M, Papadopoulos V. Peripheral-type benzodiazepine receptor-mediated action of steroidogenic acute regulatory protein on cholesterol entry into leydig cell mitochondria. Mol. Endocrinol 2005;19:540-554. [PubMed: 15498831]

11. Wright G, Reichenbecher V. The effects of superoxide and the peripheral benzodiazepine receptor ligands on the mitochondrial processing of manganese-dependent superoxide dismutase. Exp. Cell Res 1999;246:443-450. [PubMed: 9925760]

12. Falchi AM, Battetta B, Sanna F, Piludu M, Sogos V, Serra M, Melis M, Putzolu M, Diaz G. Intracellular cholesterol changes induced by translocator protein $(18 \mathrm{kDa}) \mathrm{TSPO} / \mathrm{PBR}$ ligands. Neuropharmacology 2007;53:318-329. [PubMed: 17631921]

13. Levin E, Premkumar A, Veenman L, Kugler W, Leschiner S, Spanier I, Weisinger G, Lakomek M, Weizman A, Snyder SH, Pasternak GW, Gavish M. The peripheral-type benzodiazepine receptor and tumorigenicity: isoquinoline binding protein (IBP) antisense knockdown in the C6 glioma cell line. Biochemistry 2005;44:9924-9935. [PubMed: 16026165]

14. Shoukrun R, Veenman L, Shandalov Y, Leschiner S, Spanier I, Karry R, Katz Y, Weisinger G, Weizman A, Gavish M. The 18-kDa translocator protein, formerly known as the peripheral-type benzodiazepine receptor, confers proapoptotic and antineoplastic effects in a human colorectal cancer cell line. Pharmacogenet. Genomics 2008;18:977-988. [PubMed: 18806692]

15. Veenman L, Papadopoulos V, Gavish M. Channel-like functions of the 18-kDa translocator protein (TSPO): regulation of apoptosis and steroidogenesis as part of the host-defense response. Curr. Pharm. Des 2007;13:2385-2405. [PubMed: 17692008]

16. Stojanovski D, Johnston AJ, Streimann I, Hoogenraad NJ, Ryan MT. Import of nuclear-encoded proteins into mitochondria. Exp. Physiol 2003;88:57-64. [PubMed: 12525855]

17. Rehling P, Brandner K, Pfanner N. Mitochondrial import and the twin-pore translocase. Nat. Rev. Mol. Cell Biol 2004;5:519-530. [PubMed: 15232570] 
18. Neupert W, Herrmann JM. Translocation of proteins into mitochondria. Annu. Rev. Biochem 2007;76:723-749. [PubMed: 17263664]

19. Rapaport D. Finding the right organelle. Targeting signals in mitochondrial outer-membrane proteins. EMBO Rep 2003;4:948-952. [PubMed: 14528265]

20. Rapaport D. How does the TOM complex mediate insertion of precursor proteins into the mitochondrial outer membrane? J. Cell Biol 2005;171:419-423. [PubMed: 16260501]

21. Kunkele KP, Heins S, Dembowski M, Nargang FE, Benz R, Thieffry M, Walz J, Lill R, Nussberger $\mathrm{S}$, Neupert W. The preprotein translocation channel of the outer membrane of mitochondria. Cell 1998;93:1009-1019. [PubMed: 9635430]

22. Chan NC, Likic VA, Waller RF, Mulhern TD, Lithgow T. The C-terminal TPR domain of Tom70 defines a family of mitochondrial protein import receptors found only in animals and fungi. J. Mol. Biol 2006;358:1010-1022. [PubMed: 16566938]

23. Young JC, Hoogenraad NJ, Hartl FU. Molecular chaperones Hsp90 and Hsp70 deliver preproteins to the mitochondrial import receptor Tom70. Cell 2003;112:41-50. [PubMed: 12526792]

24. Fan AC, Bhangoo MK, Young JC. Hsp90 functions in the targeting and outer membrane translocation steps of Tom70-mediated mitochondrial import. J. Biol. Chem 2006;281:33313-33324. [PubMed: 16968702]

25. Bhangoo MK, Tzankov S, Fan AC, Dejgaard K, Thomas DY, Young JC. Multiple 40-kDa heat-shock protein chaperones function in Tom70-dependent mitochondrial import. Mol. Biol. Cell 2007;18:3414-3428. [PubMed: 17596514]

26. Lan L, Isenmann S, Wattenberg BW. Targeting and insertion of C-terminally anchored proteins to the mitochondrial outer membrane is specific and saturable but does not strictly require ATP or molecular chaperones. Biochem. J 2000;349:611-621. [PubMed: 10880361]

27. Paschen SA, Neupert W, Rapaport D. Biogenesis of beta-barrel membrane proteins of mitochondria. Trends Biochem. Sci 2005;30:575-582. [PubMed: 16126389]

28. Pfanner N, Wiedemann N, Meisinger C, Lithgow T. Assembling the mitochondrial outer membrane. Nat. Struct. Mol. Biol 2004;11:1044-1048. [PubMed: 15523480]

29. Kozjak-Pavlovic V, Ross K, Benlasfer N, Kimmig S, Karlas A, Rudel T. Conserved roles of Sam50 and metaxins in VDAC biogenesis. EMBO Rep 2007;8:576-582. [PubMed: 17510655]

30. Kozjak V, Wiedemann N, Milenkovic D, Lohaus C, Meyer HE, Guiard B, Meisinger C, Pfanner N. An essential role of Sam50 in the protein sorting and assembly machinery of the mitochondrial outer membrane. J. Biol. Chem 2003;278:48520-48523. [PubMed: 14570913]

31. Armstrong LC, Saenz AJ, Bornstein P. Metaxin 1 interacts with metaxin 2, a novel related protein associated with the mammalian mitochondrial outer membrane. J. Cell Biochem 1999;74:11-22. [PubMed: 10381257]

32. Armstrong LC, Komiya T, Bergman BE, Mihara K, Bornstein P. Metaxin is a component of a preprotein import complex in the outer membrane of the mammalian mitochondrion. J. Biol. Chem 1997;272:6510-6518. [PubMed: 9045676]

33. Otera H, Taira Y, Horie C, Suzuki Y, Suzuki H, Setoguchi K, Kato H, Oka T, Mihara K. A novel insertion pathway of mitochondrial outer membrane proteins with multiple transmembrane segments. J. Cell Biol 2007;179:1355-1363. [PubMed: 18158327]

34. Liu J, Rone MB, Papadopoulos V. Protein-protein interactions mediate mitochondrial cholesterol transport and steroid biosynthesis. J. Biol. Chem 2006;281:38879-38893. [PubMed: 17050526]

35. Krueger KE, Papadopoulos V. Peripheral-type benzodiazepine receptors mediate translocation of cholesterol from outer to inner mitochondrial membranes in adrenocortical cells. J. Biol. Chem 1990;265:15015-15022. [PubMed: 2168398]

36. Simpson, RJ. Proteins and proteomics a laboratory manual. Cold Spring Harbor Laboratory Press; Cold Spring Harbor, NY: 2003.

37. Fujiki Y, Hubbard AL, Fowler S, Lazarow PB. Isolation of intracellular membranes by means of sodium carbonate treatment: application to endoplasmic reticulum. J. Cell Biol 1982;93:97-102. [PubMed: 7068762]

38. Zara V, Palmieri F, Mahlke K, Pfanner N. The cleavable presequence is not essential for import and assembly of the phosphate carrier of mammalian mitochondria but enhances the specificity and efficiency of import. J. Biol. Chem 1992;267:12077-12081. [PubMed: 1534805] 
39. Wilm M, Shevchenko A, Houthaeve T, Breit S, Schweigerer L, Fotsis T, Mann M. Femtomole sequencing of proteins from polyacrylamide gels by nano-electrospray mass spectrometry. Nature 1996;379:466-469. [PubMed: 8559255]

40. Hales KH, Diemer T, Ginde S, Shankar BK, Roberts M, Bosmann HB, Hales DB. Diametric effects of bacterial endotoxin lipopolysaccharide on adrenal and Leydig cell steroidogenic acute regulatory protein. Endocrinology 2000;141:4000-4012. [PubMed: 11089530]

41. Li H, Yao Z, Degenhardt B, Teper G, Papadopoulos V. Cholesterol binding at the cholesterol recognition/ interaction amino acid consensus (CRAC) of the peripheral-type benzodiazepine receptor and inhibition of steroidogenesis by an HIV TAT-CRAC peptide. Proc. Natl. Acad. Sci. U. S. A 2001;98:1267-1272. [PubMed: 11158628]

42. Delavoie F, Li H, Hardwick M, Robert JC, Giatzakis C, Peranzi G, Yao ZX, Maccario J, Lacapere JJ, Papadopoulos V. In vivo and in vitro peripheral-type benzodiazepine receptor polymerization: functional significance in drug ligand and cholesterol binding. Biochemistry 2003;42:4506-4519. [PubMed: 12693947]

43. Young JC, Hartl FU. Polypeptide release by Hsp90 involves ATP hydrolysis and is enhanced by the co-chaperone p23. EMBO J 2000;19:5930-5940. [PubMed: 11060043]

44. Marcu MG, Chadli A, Bouhouche I, Catelli M, Neckers LM. The heat shock protein 90 antagonist novobiocin interacts with a previously unrecognized ATP-binding domain in the carboxyl terminus of the chaperone. J. Biol. Chem 2000;275:37181-37186. [PubMed: 10945979]

45. Jamin N, Neumann JM, Ostuni MA, Vu TK, Yao ZX, Murail S, Robert JC, Giatzakis C, Papadopoulos V, Lacapere JJ. Characterization of the cholesterol recognition amino acid consensus sequence of the peripheral-type benzodiazepine receptor. Mol. Endocrinol 2005;19:588-594. [PubMed: 15528269]

46. Viguera AR, Serrano L. Experimental analysis of the Schellman motif. J. Mol. Biol 1995;251:150160. [PubMed: 7643384]

47. Li W, Amri H, Huang H, Wu C, Papadopoulos V. Gene and protein profiling of the response of MA-10 Leydig tumor cells to human chorionic gonadotropin. J. Androl 2004;25:900-913. [PubMed: 15477362]

48. Walther DM, Rapaport D. Biogenesis of mitochondrial outer membrane proteins. Biochim. Biophys. Acta 2009;1793:42-51. [PubMed: 18501716]

49. Rone MB, Fan J, Papadopoulos V. Cholesterol transport in steroid biosynthesis: Role of proteinprotein interactions and implications in disease states. Biochim. Biophys. Acta. 2009

50. Liu J, Rone MB, Papadopoulos V. Protein-protein interactions mediate mitochondrial cholesterol transport and steroid biosynthesis. J. Biol. Chem 2006;281:38879-38893. [PubMed: 17050526]

51. Thomson M. Molecular and cellular mechanisms used in the acute phase of stimulated steroidogenesis. Horm. Metab Res 1998;30:16-28. [PubMed: 9503034]

52. Brdiczka DG, Zorov DB, Sheu SS. Mitochondrial contact sites: their role in energy metabolism and apoptosis. Biochim. Biophys. Acta 2006;1762:148-163. [PubMed: 16324828]

53. Reichert AS, Neupert W. Contact sites between the outer and inner membrane of mitochondria-role in protein transport. Biochim. Biophys. Acta 2002;1592:41-49. [PubMed: 12191767] 
A

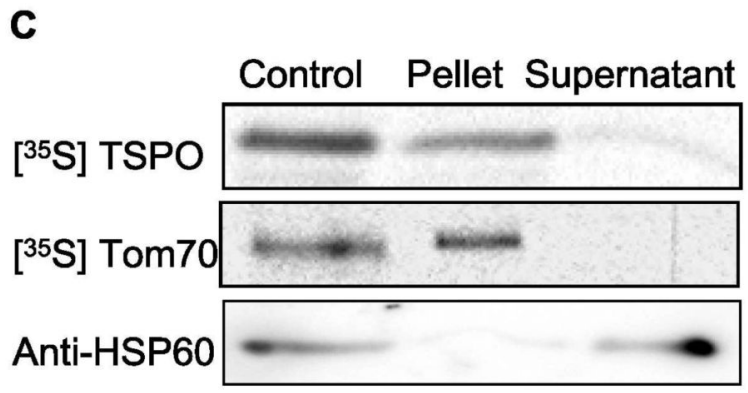

Figure 1. Identification of TSPO import complexes in the OMM

A) Isolated mitochondria from HeLa cells were incubated with in vitro-transcribed/translated $\left[{ }^{35} \mathrm{~S}\right]$-TSPO. The BN-PAGE gel was transferred to PVDF and exposed to a multipurpose phosphor screen (left panel) or blotted with antisera against TSPO, Tom 40, and Tom22 (right panel). B) In vitro-transcribed/translated TSPO import into mitochondria examined at either 4 ${ }^{\circ} \mathrm{C}$ or $33^{\circ} \mathrm{C}$; at the stated time points, one-half of the import reaction was treated with proteinase $\mathrm{K}$ and both samples were analyzed by BN-PAGE. C) In vitro-transcribed/translated $\left[{ }^{35} \mathrm{~S}\right]-$ TSPO and $\left[{ }^{35} \mathrm{~S}\right]$-Tom70 were incubated with HeLa cell mitochondria and treated with sodium carbonate for 30 minutes. 

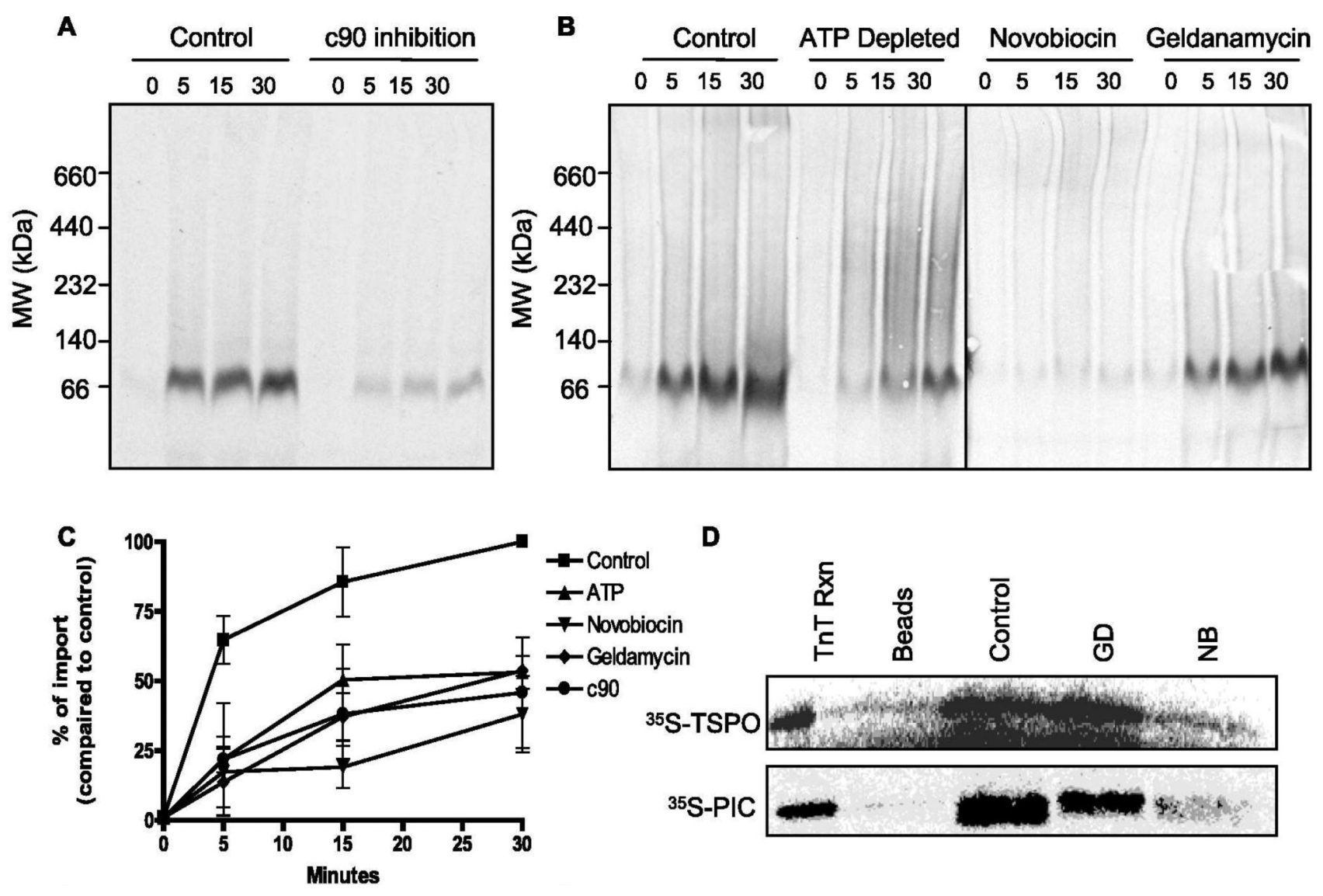

\section{D}

Figure 2. TSPO import is dependent upon heat shock proteins and ATP for import

A) Effects of C90 incubation with TSPO. TSPO was imported as described above (control). B) Effect of ATP depletion, $18 \mu \mathrm{M}$ geldanamycin, and $1 \mathrm{mM}$ novobiocin on TSPO import. C) Quantification of imported TSPO. Results shown are means \pm sem from three independent experiments. D) Nickel-sepharose pull-down assay of ${ }^{35} \mathrm{~S}$-TSPO and ${ }^{35} \mathrm{~S}$-PIC. When indicated geldanamycin or novobiocin were added to the reaction mixture. 
A

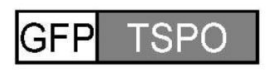

B $\quad 1-7$

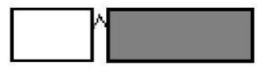

C

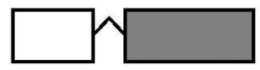

D $\quad 1-48$

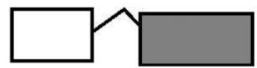

$\mathbf{E}$

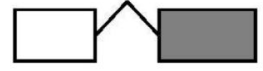

F $1-85$

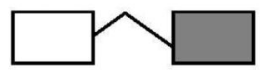

G $\quad 1-110$
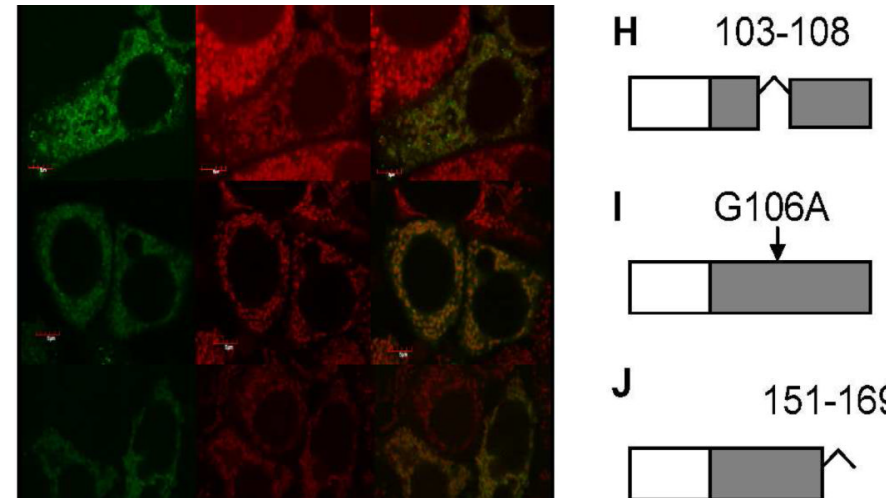

$\mathbf{J}$

$151-169$
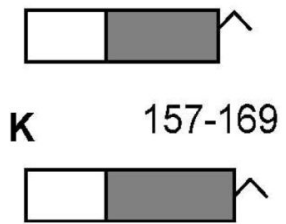

$\mathbf{L}$

$148-157$
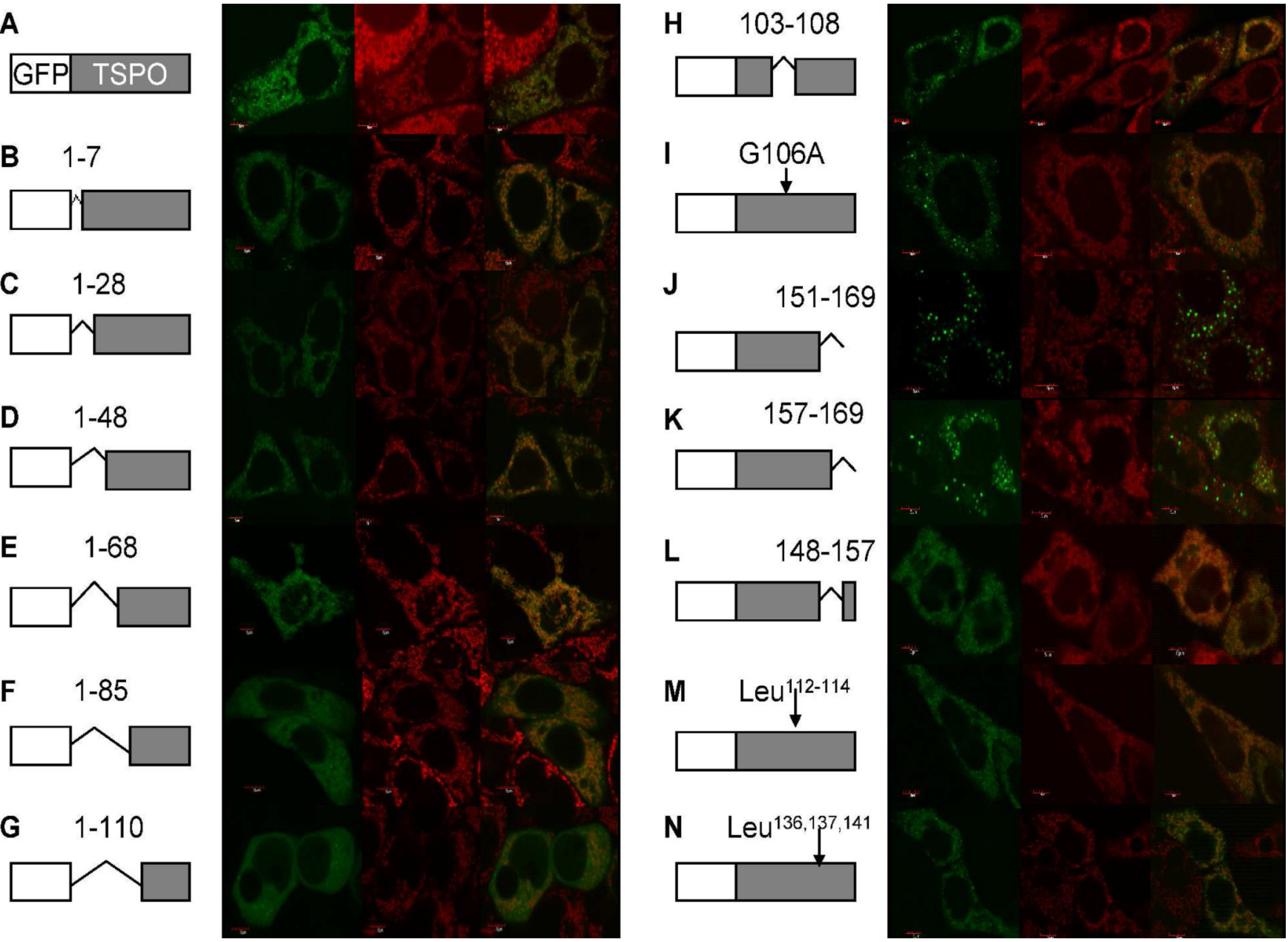

Figure 3. Identification of the TSPO amino acid sequence(s) responsible for targeting the protein to the OMM

MA-10 cells were transfected with either wild-type GFP-TSPO or various constructs of GFPTSPO, stained with Mitotracker CMX and visualized by confocal microscopy. Each panel shows the construct used, GFP fluorescence, mitochondrial staining, and the merged image. A) Wild-type TSPO with GFP linked to the N-terminus. Cells were also transfected with GFP$\Delta$ 1-7-TSPO (B), GFP- $\Delta 1$-28-TSPO (C), GFP- $\Delta 1$-48-TSPO (D), GFP- $\Delta 1-68$-TSPO (E), GFP- $\Delta 1-85$-TSPO (F), GFP- $\Delta 1-110-$ TSPO (G), GFP- $\Delta 151-169-T S P O(J)$, GFP- $\Delta 157$ $-169-\mathrm{TSPO}(\mathrm{K})$. The cholesterol binding domain, GFP- $\Delta 148-157-\mathrm{TSPO}(\mathrm{L})$, or the Schellman motif, GFP- $\Delta 103-108$-TSPO $(\mathrm{H})$ were removed and transfected. Construct GFP-G106ATSPO (I) point mutation altering the Schellman motif and constructs GFP-Leucine ${ }^{112-114}$ TSPO (M) and GFP-Leucine ${ }^{137,138,141}$-TSPO $(\mathrm{N})$ were also transfected as described under experimental methods. 
A

C

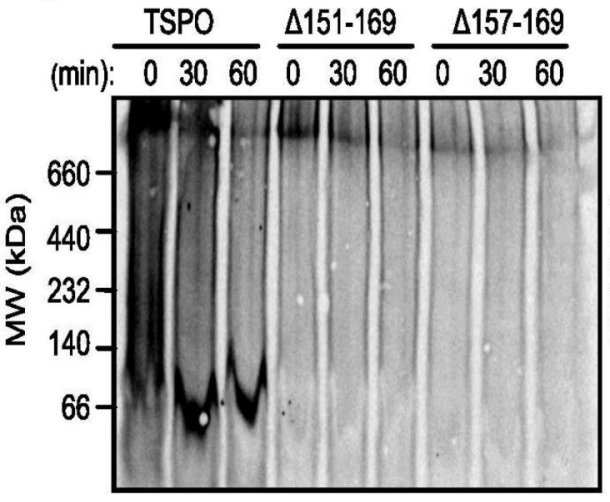

E

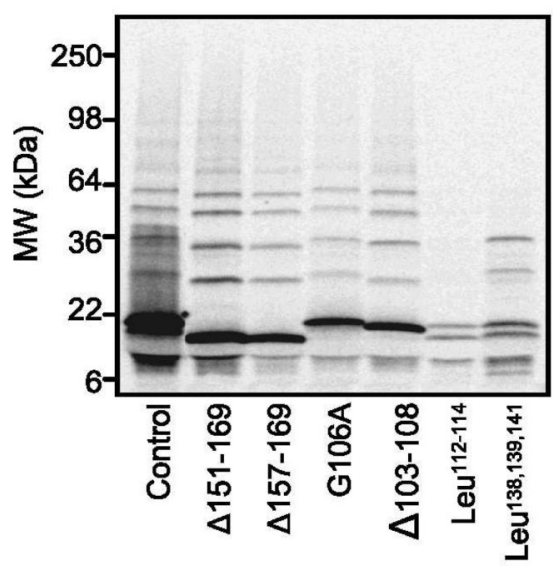

B

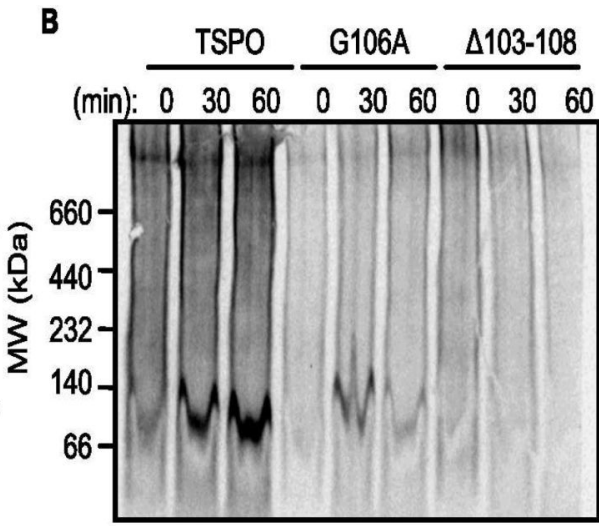

D

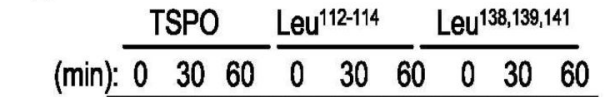

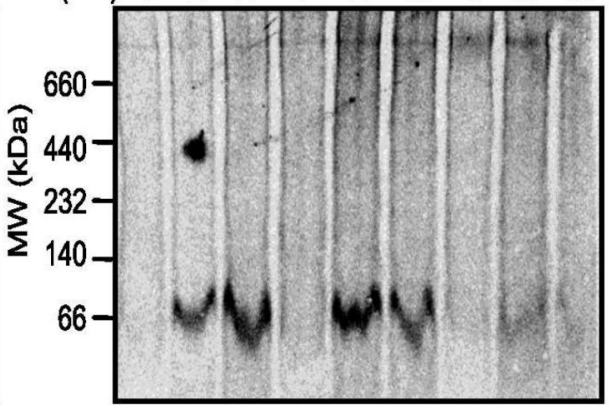

$\mathbf{F}$

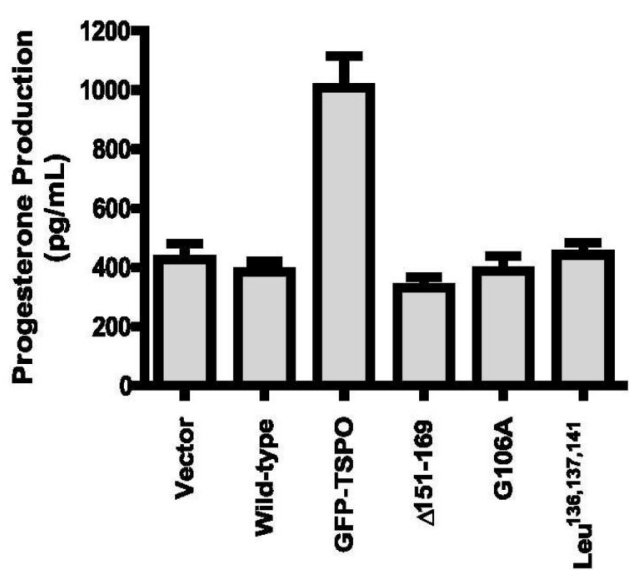

Figure 4. TSPO protein regions and amino acids required for insertion into the OMM A) Model of the 18-kDa TSPO protein present in the OMM. Blue amino acids represent the $\mathrm{C}$-terminus, red amino acids represent the mutated leucine residues, and green amino acids show the Schellman motif with the yellow amino acid in the middle representing the mutated glycine. B) Schellman motif mutants of the TSPO protein were compared with wild-type TSPO for import into HeLa cells mitochondria, followed by analysis by BN-PAGE. C) Effect of removal of the C-terminus with constructs $\Delta 157-169$ and $\Delta 151-169$ on inhibition of TSPO import into isolated mitochondria. D) Effect of leucine mutations on in vitro-transcribed/ translated radiolabeled TSPO import into HeLa cell mitochondria. E) SDS-PAGE of radiolabeled constructs from import studies for confirmation of size due to mutations. F) 
Measurement of progesterone production produced by MA-10 was performed as stated in the methods. Results shown are means \pm SEM from three independent experiments $(n=9)$. 

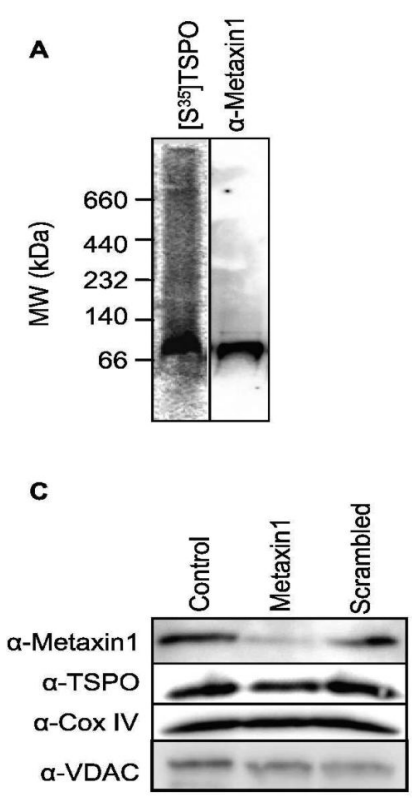

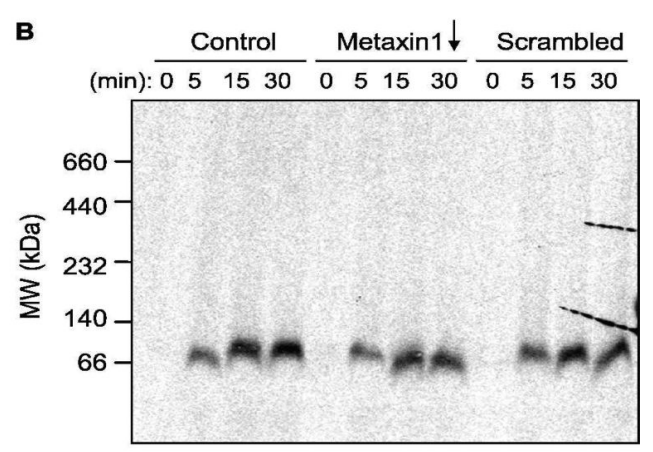

D

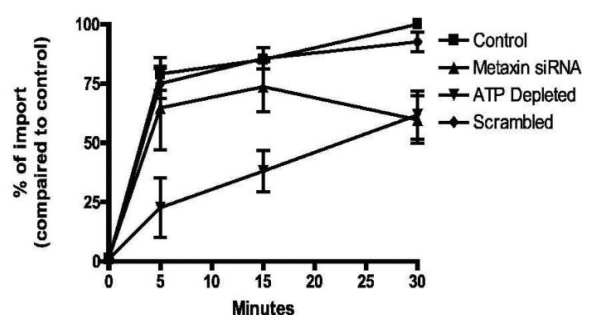

Figure 5. TSPO import is dependent on Metaxin 1

A) MA-10 mitochondria incubated with in vitro-transcribed/translated TSPO analyzed by BNPAGE, and blotted with anti-metaxin 1 antibody. B) In vitro-transcribed/translated TSPO incubated with mitochondria isolated from MA-10 cells control, Metaxin 1-depleted, and MA-10 cells treated with scrambled siRNAs. C) Immunoblot analysis for Metaxin1, COX IV, TSPO and VDAC in mitochondria isolated form MA-10 cells treated with the various siRNAs. D) Quantification of imported TSPO. Results shown are means \pm sem from three independent experiments. 

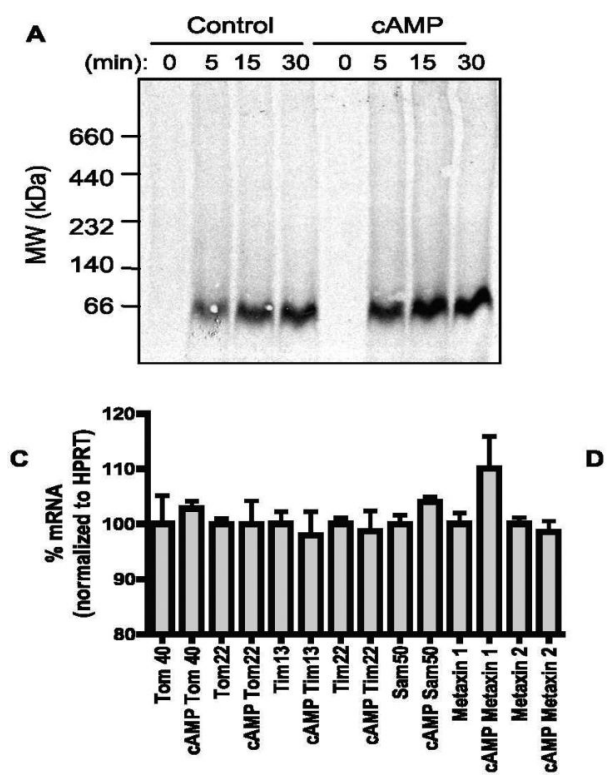
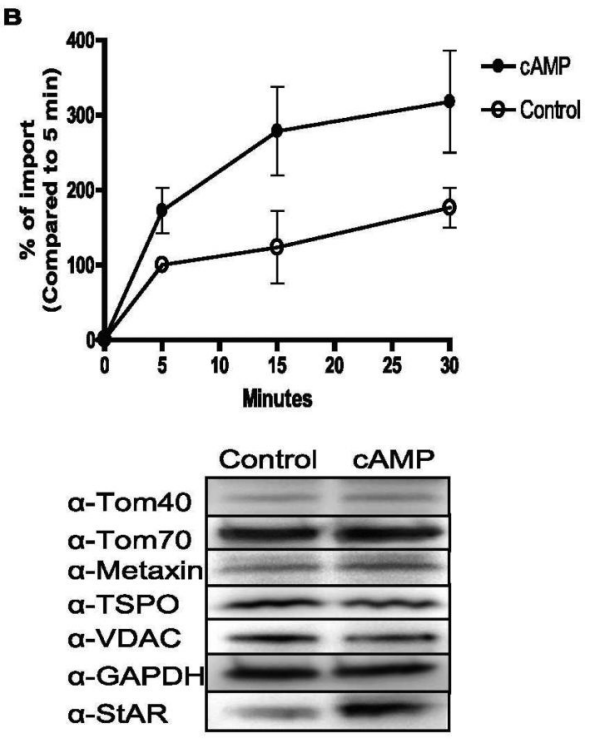

Figure 6. TSPO import is increased with cAMP stimulated mitochondria A) Mitochondria isolated from MA-10 cells incubated with $+/-1 \mathrm{mM}$ cAMP were incubated with radiolabeled TSPO, analyzed via BN-PAGE. B) Quantification of imported TSPO, results shown are means \pm sem from three independent experiments. C) RT-qPCR analysis of MA-10 RNA +/- 1mM cAMP. D) Immunoblot analysis of MA-10 cells incubated with and without $1 \mathrm{mM}$ 8-bromo-AMP. 


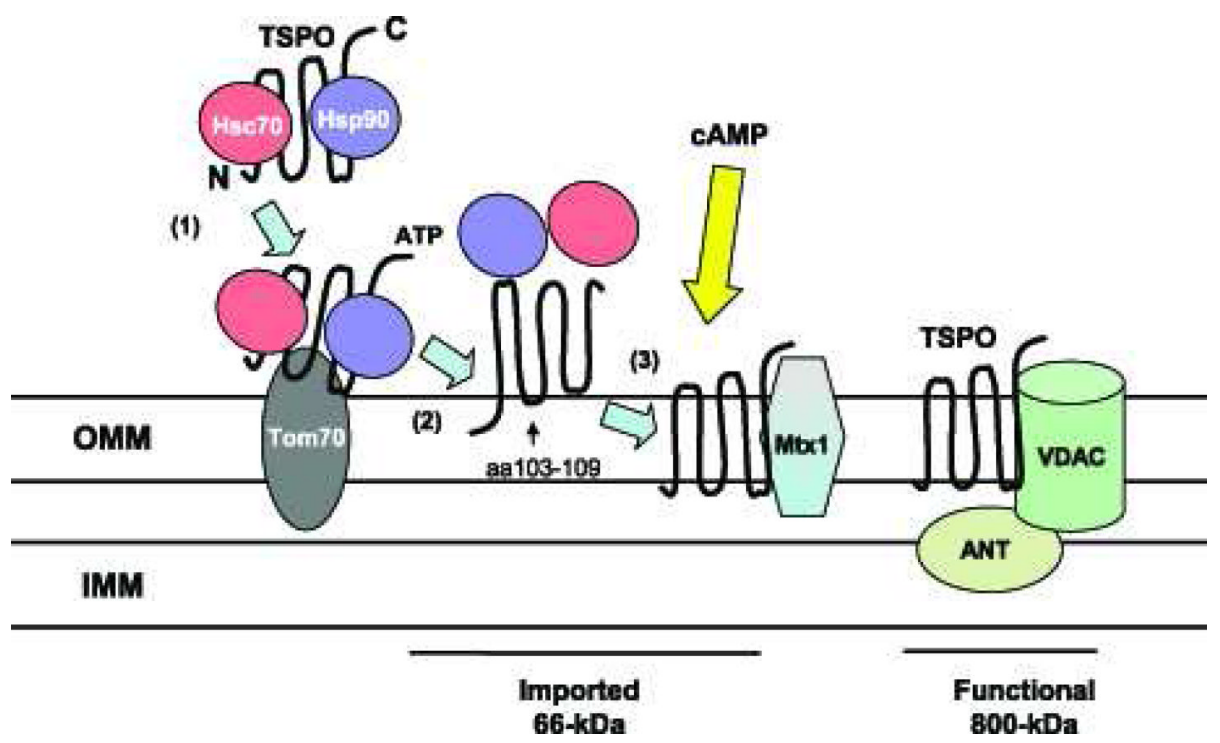

Figure 7. TSPO import into the OMM

We have outlined the steps necessary for TSPO targeting and insertion into the OMM. (1) TSPO is targeted to the OMM through its interactions with cytosolic chaperones, Hsc70 and Hsp90. (2) At the OMM, TSPO interacts with Tom70 and is released from the chaperones in an ATP-dependent manner. (3) TSPO insertion into the OMM is dependent upon Metaxin 1 (Mtx1) and TSPO structure, where both the C-terminus and the Schellman motif (amino acids 103-108) are necessary to form a 66-kDa complex. Once import is complete, TSPO associates with other protein complexes found in the OMM identified previously as VDAC and ANT. Yellow arrow indicates possible step accelerated by cAMP treatment. 
Table 1

Primers used for Q-PCR analysis:

\begin{tabular}{|c|c|c|c|}
\hline Gene & Forward Primer & Reverse Primer & Amplicon \\
\hline $\begin{array}{c}\text { Tom40 } \\
\text { (NM_001109748) }\end{array}$ & CGGTGTGGATGGCGAGTACCG & CCTGAACCCACCAAGACATCTG & 81 \\
\hline $\begin{array}{c}\text { Tom22 } \\
\text { (NM_172609) }\end{array}$ & CGGGCCGAGGAATTACTCCCG & CGTCTTCTTCCAGCTCCTCCTC & 64 \\
\hline $\begin{array}{c}\text { Tim } 13 \\
\text { (NM_013898) }\end{array}$ & CGATAGGCTCCTTGGATAACTCG & AGAGTTGTAGGCGCGGGACAC & 98 \\
\hline $\begin{array}{c}\text { Tim22 } \\
\text { (NM_019818) }\end{array}$ & GTACCTGGTGGGCGACAAGC & CGAGTCGCTCTTGGCAGGACTCG & 85 \\
\hline $\begin{array}{c}\text { Sam50 } \\
\text { (NM_178614) }\end{array}$ & GTGCATCCGCTGGTCCTATG & CGGCGTAGTTCAGCTCCAGCCG & 77 \\
\hline $\begin{array}{c}\text { Metaxin 1 } \\
\text { (NM_013604) } \\
\end{array}$ & CGGTAGAGGAGGAGCCATACCG & TGGATAGAAACGATGCCACTGA & 106 \\
\hline $\begin{array}{c}\text { Metaxin } 2 \\
\text { (NM_016804) } \\
\end{array}$ & CGTTTGCAGTGGGAAGTGAAACG & CCTGGTCCAGAGTCTTGTTACCC & 67 \\
\hline $\begin{array}{c}\text { HPRT } \\
\text { (NM_013556) }\end{array}$ & GTACCAGACCTCTCGAAGTGTTGGATAC & TCCAACAACAAACTTGTCTGGAAT & 77 \\
\hline
\end{tabular}


Table 2

Identification of proteins present in the 66- and 800-kDa HeLa protein complexes by mass spectrometry

The imported 66-kDa TSPO complex and the endogenous 800-kDa mitochondrial protein complexes separated by BN-PAGE and 2D SDS-PAGE were analyzed by mass spectrometry; some of the major identified proteins are shown.

\begin{tabular}{|c|c|}
\hline Protein & Sequences Identified \\
\hline \multicolumn{2}{|l|}{ 66-kDa } \\
\hline Metaxin1 & RSLASPGISPGPLTATIGGAVAGGGPR \\
\hline Nonspecific lipid-transfer protein & $\begin{array}{l}\text { K.LQNLQLQPGNAKL } \\
\text { K.IGGIFAFK.V } \\
\text { K.ANLVFKEIEK.K }\end{array}$ \\
\hline Voltage-dependent anion channel (VDAC 1) & $\begin{array}{l}\text { TDEFQLHTNVNDGTEFGGSIYQK } \\
\text { R.WTEYGLTFTEK.W } \\
\text { K.LTFDSSFSPNTGK.K }\end{array}$ \\
\hline \multicolumn{2}{|l|}{ 800-kDa } \\
\hline Adenine nucleotide translocator (ANT $1,2,3$ ) & $\begin{array}{l}\text { K.LLLQVQHASK.Q } \\
\text { R.YFPTQALNFAFK.D } \\
\text { R.AAYFGIYDTAK.G } \\
\text { K.DFLAGGIAAAISK.T }\end{array}$ \\
\hline Apolipoprotein A-I & K.VSFLSALEEYTK.K \\
\hline Apolipoprotein A-II & K.SPELQAEAK.S \\
\hline Fatty acid synthase & $\begin{array}{l}\text { K.VVVQVLAEEPEAVLK.G } \\
\text { R.LQVVDQPLPVR.G } \\
\text { K.VGDPQELNGITR.A }\end{array}$ \\
\hline Mitofilin & R.ELDSITPEVLPGWK.G \\
\hline Voltage-dependent anion channel (VDAC 1,3) & $\begin{array}{l}\text { R.VTQSNFAVGYK.T } \\
\text { K.LSQNNFALGYK.A }\end{array}$ \\
\hline Annexin A2 & $\begin{array}{l}\text { K.SALSGHLETVILGLLK.T } \\
\text { R.QDIAFAYQR.R } \\
\text { K.TPAQYDASELK.A } \\
\text { K.GVDEVTIVNILTNR.S }\end{array}$ \\
\hline
\end{tabular}

